\title{
Attributing tropical cyclogenesis to equatorial waves in the western North Pacific
}

\author{
Carl J. Schreck, III ${ }^{1}$, John Molinari ${ }^{1}$, and Karen I. Mohr ${ }^{2}$ \\ ${ }^{1}$ Department of Atmospheric and Environmental Sciences, University at Albany, \\ State University of New York, Albany, New York \\ ${ }^{2}$ Laboratory for Atmospheres, NASA Goddard Space Flight Center, Greenbelt, Maryland
}

Submitted to Journal of the Atmospheric Sciences

Submitted 1 December 2009

Corresponding author address:

Carl J. Schreck, III

Department of Atmospheric and Environmental Sciences, ES-351

University at Albany/SUNY

Albany, NY 12222.

carl@atmos.albany.edu 


\begin{abstract}
The direct influences of equatorial waves on the genesis of tropical cyclones are evaluated. Tropical cyclogenesis is attributed to an equatorial wave when the filtered rainfall anomaly exceeds a threshold value at the genesis location. For an attribution threshold of $3 \mathrm{~mm} /$ day, $51 \%$ of warm season western North Pacific tropical cyclones are attributed to tropical depression (TD)-type disturbances, $29 \%$ to equatorial Rossby waves, $26 \%$ to mixed Rossby-Gravity waves, $23 \%$ to Kelvin waves, $13 \%$ to the Madden-Julian oscillation (MJO), and 19\% are not attributed to any equatorial wave. The fraction of tropical cyclones attributed to TD-type disturbances is consistent with previous findings. Past studies have also demonstrated that the MJO significantly modulates tropical cyclogenesis, but fewer storms are attributed to the MJO than any other wave type. This disparity arises from the difference between attribution and modulation. The MJO produces broad regions of favorable conditions for cyclogenesis, but the MJO alone might not determine when and where a storm will develop within these regions.
\end{abstract}

Tropical cyclones contribute less than $17 \%$ of the power in any portion of the equatorial wave spectrum because tropical cyclones are relatively uncommon equatorward of $15^{\circ}$ latitude. In regions where they are active, however, tropical cyclones can contribute more than $20 \%$ of the warm season rainfall and up to $50 \%$ of the total variance. Tropical cyclone-related anomalies can significantly contaminate wave-filtered precipitation at the location of genesis. To mitigate this effect, the tropical cyclonerelated rainfall anomalies were removed before filtering in this study. 


\section{Introduction}

A significant portion of tropical convective variability has been linked with convectively coupled equatorial waves (Kiladis et al. 2009). These waves include equatorial Rossby (ER) waves, mixed Rossby-gravity (MRG) waves, and Kelvin waves. The Madden-Julian Oscillation (MJO; Zhang 2005) is another prominent source of convective variability that consists of convectively forced equatorial waves, but it does not follow any equatorial wave dispersion relation. Tropical depression (TD)-type disturbances are also wavelike systems that are sometimes called easterly waves. In the western North Pacific, TD-type disturbances propagate westward with periods of 3-9 days and wavelengths of 2500-4000 km (Reed and Recker 1971; Lau and Lau 1990; Takayabu and Nitta 1993; Dunkerton and Baldwin 1995; Chang et al. 1996). For brevity, all of these features will be referred to as equatorial waves because they reside in equatorial regions and share wavelike properties.

Equatorial waves also influence tropical cyclogenesis (Liebmann et al. 1994; Dickinson and Molinari 2002; Bessafi and Wheeler 2006; Frank and Roundy 2006; Molinari et al. 2007; Schreck and Molinari 2009). Dickinson and Molinari (2002) studied three tropical cyclones that formed as a packet of MRG waves transitioned to TD-type structures. Each storm developed on the northeastern edge of the Northern Hemispheric cyclonic anomalies where the idealized MRG wave favors convection. In another case study, Molinari et al. (2007) examined an ER wave packet that led to eight tropical cyclones over 2.5 months. Similar to the MRG waves from Dickinson and Molinari (2002), these storms formed on the eastern edge of the cyclonic ER waves where the convection was strongest. Schreck and Molinari (2009) investigated three sets of twin 
tropical cyclones that developed within one month. These twins were associated with another series of ER waves. The waves combined with a favorable low-frequency background to enhance convection and low-level cyclonic vorticity for each storm's genesis. Together these case studies have shown that equatorial waves can stimulate cyclogenesis by enhancing the background convection and low-level cyclonic vorticity.

TD-type disturbances have been frequently associated with tropical cyclogenesis. Ritchie and Holland (1999) examined the large-scale patterns associated with tropical cyclogenesis in the western North Pacific over 8 years. Out of 199 storms, $47 \%$ developed within TD-type disturbances. The majority of these tropical cyclones formed when the disturbance entered the monsoon confluence region. Fu et al. (2007) similarly found that TD-type disturbances were associated with 53\% of the 34 western North Pacific tropical cyclones from 2000 and 2001. Four of these TD-type disturbances originated from MRG waves as in Dickinson and Molinari (2002).

Tropical cyclones produce large local anomalies that significantly contribute to the mean and variance of a variety of meteorological fields. For Pacific islands near $125^{\circ} \mathrm{E}$, tropical cyclones generate $24 \%-62 \%$ of the July-October rainfall (Kubota and Wang 2009; Hsu et al. 2008). The highest percentages were observed near Taiwan, while tropical cyclones tend to have a smaller influence on rainfall at lower latitudes (Rodgers et al. 2000; Kubota and Wang 2009).

The tropical cyclone-related anomalies can also project onto the filter bands typically used to identify equatorial waves. For example, they contribute more than half of the intraseasonal (20-80-day) variance of vorticity in some portions of the western North Pacific (Hsu et al. 2008). These effects have often been ignored in previous studies 
of equatorial waves. Section 3 demonstrates a method proposed by A. Aiyyer (2007, personal communication) for identifying and removing the tropical cyclone-related anomalies. This method will also be used to estimate the contamination of the equatorial wave power spectrum by tropical cyclones.

\section{Modulation and attribution}

Previous climatological studies (e.g., Liebmann et al. 1994; Bessafi and Wheeler 2006; Frank and Roundy 2006) have focused on the modulation of tropical cyclones by equatorial waves. These studies counted the number of storms that formed during each phase of a given wave type. If significantly more storms developed in one phase compared to another, then this modulation demonstrated a relationship between the waves and cyclogenesis.

In the western North Pacific and Indian Oceans, for example, Liebmann et al. (1994) found that twice as many tropical cyclones developed in association with negative (convective) MJO-filtered OLR anomalies than with positive anomalies. Similarly, Frank and Roundy (2006) observed negative wave-filtered OLR anomalies at 55\%-85\% of genesis locations depending on the basin and the equatorial wave type. Bandpass filtered

data is roughly distributed equally between positive and negative anomalies. Even if no relationship existed between tropical cyclogenesis and equatorial waves, then just by chance about $50 \%$ of the genesis locations would have filtered anomalies with a favorable sign. Frank and Roundy determined that tropical cyclogenesis was actually significantly more likely to occur within negative OLR anomalies. 
Bessafi and Wheeler (2006) used a different method to examine the modulation of tropical cyclones by equatorial waves in the south Indian Ocean. They used principal component (PC) indices to determine the phase of each equatorial wave. Six "active" categories were defined based on the angle of the two leading PCs, and a "weak" category was defined for PC-vector magnitudes less than one standard deviation. They examined the modulation by counting the number of storms that formed basin-wide during each category. The MJO, ER waves, and Kelvin waves each produced significant basin-wide modulations of cyclogenesis. For these waves, at least twice as many storms developed during the most favorable phase compared with the least favorable phase.

The present study will take a different approach and will investigate the fraction of tropical cyclone formations that equatorial waves directly influenced. This type of attribution requires a more stringent threshold than simply a favorably signed anomaly. In addition, basin-wide metrics cannot determine attribution. Tropical cyclogenesis is a local process, so attribution should depend only on the waves' influences at the genesis location and time.

A relatively simple method will be used to determine which tropical cyclone formations may be attributed to equatorial waves using rainfall data. The first step is to remove the tropical cyclone-related anomalies as described in section 3 . The remaining precipitation fields are then filtered for each equatorial wave type. If the filtered anomaly in the $1^{\circ}$ grid box containing the genesis location exceeds a threshold value, then the tropical cyclone is attributed to that equatorial wave. The results of these attributions, including their sensitivity to the threshold selection, will be explored in section 4 . 


\section{Data}

Tropical cyclone tracks are obtained from the National Climate Data Center's (NCDC) International Best Track Archive for Climate Stewardship (IBTrACS; Knapp et al. 2009). This dataset merges tropical cyclone data from operational centers around the world. Tropical cyclogenesis in the present study will be defined as the first time a storm achieves maximum 10-min sustained winds of at least $13 \mathrm{~m} \mathrm{~s}^{-1}$ (25 knots). This study will focus on cyclogenesis in the western North Pacific, defined as the region from the equator to $20^{\circ} \mathrm{N}$ and $120^{\circ} \mathrm{E}$ to the dateline. Only those storms that formed during the warm seasons (May-November) from 1998 to 2007 will be considered.

The equatorial waves will be identified using the Tropical Rainfall Measuring Mission (TRMM) multisatellite precipitation analysis (TMPA; TRMM product 3B42; Huffman et al. 2007). This dataset merges precipitation estimates from passive microwave sensors on a suite of low earth-orbiting satellites. Gaps between low earthorbiting passes are filled using geostationary infrared data. The resulting precipitation estimates are then calibrated using global analyses of monthly rain gauge data. The TMPA data are available from 1998 onward on 3-hourly $0.25^{\circ}$ latitude-longitude grids, but they have been averaged to 6-hourly $1^{\circ}$ latitude-longitude grids to improve computational efficiency. The original $0.25^{\circ}$ data contained a limited number of missing values comprising less than $6 \%$ of the entire dataset. The lack of geostationary infrared coverage over the Indian Ocean before June 1998 caused most of these gaps (Huffman et al. 2007). While averaging to the coarser grid, these missing data were interpolated bilinearly in space and linearly in time from the surrounding values. The waves 
investigated in this research are sufficiently broad in scale that the results will be insensitive to the averaging and interpolation.

Figure 1 shows the wavenumber-frequency power spectrum for the TMPA rainfall rates calculated following Wheeler and Kiladis (1999). In order to focus on warm season signals, the spectra are computed for overlapping 96-day segments that begin 30 March, 1 May, 2 June, 4 July, 5 August, and 6 September in each year 1998-2007. The segments extend beyond May-November to account for the tapering that is applied to each segment. These spectra are also calculated at each latitude from the equator to $15^{\circ} \mathrm{N}$ with no equatorial symmetry constraints. The variance is then averaged from all of these latitudes and time segments, and Fig. 1a shows the base-10 logarithm of this mean spectrum.

Previous studies (e.g., Cho et al. 2004; Masunaga et al. 2006) have demonstrated the utility of similar datasets for analyzing equatorial waves, and Fig. 1 is qualitatively similar to analogous spectra of outgoing longwave radiation (OLR; Wheeler and Kiladis 1999; Roundy and Frank 2004). Some equatorial wave signals stand out even in the total spectrum (Fig. 1a). The most notable spectral peaks are associated with the MJO, Kelvin waves, and to a lesser degree MRG and ER waves. These features show more clearly in Fig. $1 \mathrm{~b}$ where the spectrum is divided by a red background following Roundy and Frank (2004).

The cyan boxes in Fig. 1 define the filter bands used to identify the equatorial waves in this study. These bands, other than the TD-band, are identical to those defined by Wheeler and Kiladis (1999). The TD-band is defined as wavenumbers from -18 to $-10(2200-4000 \mathrm{~km})$ and periods longer than 2.5 days but shorter than the MRG wave 
solution for an equivalent depth of $90 \mathrm{~m}$ (roughly 8 days). This range of wavelengths and periods is chosen to encompass previously observed characteristics of TD-type disturbances in the western Pacific (e.g., Reed and Recker 1971; Lau and Lau 1990; Takayabu and Nitta 1993; Dunkerton and Baldwin 1995; Chang et al. 1996). Kiladis et al. (2006) defined a somewhat different filter band for TD-type disturbances over West Africa. Their filter has been applied to TD-type disturbances in the Pacific Ocean (Serra et al. 2008), but it overlaps with the MRG band. The TD-band filter in Fig. 1 should distinguish TD-type disturbances from MRG waves. This filter may also be more appropriate for the western North Pacific where TD-type disturbances exhibit longer periods (Lau and Lau 1990).

\section{Tropical cyclone-related anomalies}

One possible method for investigating the influence of equatorial waves on tropical cyclogenesis is to composite many genesis events and look for evidence of the waves. Figure 2a presents a time-longitude composite of all warm season western North Pacific cyclone formations from 1998 to 2007. The shading shows the composite rainfall rates centered on the genesis time and location, which are then filtered for each equatorial wave (only the $+1 \mathrm{~mm} \mathrm{day}^{-1}$ contours are shown).

The most prominent feature in Fig. 2a is the tropical cyclone itself, which appears as a westward moving precipitation maximum. Even though this is a composite for genesis, the precipitation maximum dissipates with time. This dissipation is probably due to the tendency for tropical cyclones to move poleward away from the latitude at which they developed. 
In addition to this sharp precipitation maximum, the unfiltered data in Fig. 2a indicate broad envelopes of weaker precipitation $\left(8-16 \mathrm{~mm}_{\text {day }}{ }^{-1}\right)$ moving eastward and westward. The eastward moving envelope coincides with the MJO anomalies (cyan contour), while the westward moving envelopes roughly correspond with positive ER wave and TD-type anomalies (orange and dark red contours, respectively). The unfiltered rainfall rates associated with these features are less than $16 \mathrm{~mm} \mathrm{day}^{-1}$, which is much less than the $89 \mathrm{~mm} \mathrm{day}^{-1}$ at the genesis location.

The large precipitation maximum associated with the composite tropical cyclone can project onto many filter bands, as illustrated in Fig. 2b. Here the precipitation field (shading) is defined to be a stationary maximum with the same magnitude $\left(89 \mathrm{~mm} \mathrm{day}^{-1}\right)$ as the composite tropical cyclone. The resulting anomalies are contoured for each equatorial wave filter band at the same contour level as in Fig. 2a. This stationary maximum should be completely unrelated to any propagating equatorial wave, yet it still projects strongly onto all of the filter bands except for the MJO. These artificial anomalies are generally weaker than those associated with the real composite, but the patterns are conspicuously similar. In addition to the positive anomalies centered on the stationary maximum, the filters also produce ripples with positive anomalies in regions where the unfiltered field is zero (e.g., the positive MRG anomalies centered at \pm 4 days and $\pm 20^{\circ}$ longitude).

Figure 2 illustrates a significant obstacle to determining the influence of equatorial waves on tropical cyclones: It can be difficult to determine from filtered data which features are associated with equatorial waves and which are associated with the tropical cyclones themselves. The core dynamics of tropical cyclones produce large 
amounts of rainfall that are essentially unrelated to the dynamics of equatorial waves. Nonetheless, this intense rainfall projects onto the filtered fields.

Figure 3 uses an example from 0000 UTC 21 August 2000 to illustrate a method for isolating the tropical cyclone-related signals. At this time, a tropical depression that will later become Tropical Storm Kaemi has recently formed in the South China Sea. Meanwhile, Typhoon Billis lies to the east of the Philippines. Figure 3a shows a latitudinal cross-section of rainfall through the center of Billis. The storm is associated with intense rainfall of $261 \mathrm{~mm} \mathrm{day}^{-1}$ (red line). This rainfall rate is in the $99.9^{\text {th }}$ percentile of the warm season precipitation data in the western Pacific (not shown). By contrast, the climatological rainfall rates (black line) are generally less than $10 \mathrm{~mm} \mathrm{day}^{-1}$. Because the data are only available for 10 years, the climatology has been calculated by summing the first four harmonics of the annual cycle at each grid box. This procedure minimizes the impact of individual events on the climatology.

The tropical cyclone signal is removed by multiplying the anomalies from climatology by a Gaussian weighting function (dashed line in Fig. 3a),

$$
w=1-\exp \left(-\frac{r^{2}}{2\left(R(2 \ln 2)^{-1 / 2}\right)^{2}}\right)
$$

where $r$ is the distance from the tropical cyclone's center and $R$ is the radius at half maximum of the weighting function. The resulting rainfall rates following the tropical cyclone removal are shown by the blue line in Fig. 3a. Anomalies at the storm's center are assumed to be completely associated with the tropical cyclone, so the $261 \mathrm{~mm}^{-1}{ }^{-1}$ in Billis's core is reduced to near the climatological value of $8 \mathrm{~mm} \mathrm{day}^{-1}$. Anomalies at large distances (e.g., > $1500 \mathrm{~km}$ ) from the storm are virtually unchanged because they are 
assumed to be completely associated with the larger scale environment (including equatorial waves). Anomalies at a distance $R$ from the tropical cyclone are assumed to be half-associated with the storm and half-associated with the environment. We define this distance to be $500 \mathrm{~km}$, but the results presented in this study are not sensitive to this choice (see the appendix).

Figure $3 \mathrm{~b}$ shows a map of the total precipitation, while the anomalies attributed to tropical cyclones are shown in Fig. 3c. The weighting is applied to positive and negative rainfall anomalies alike. The core dynamics of the tropical cyclones generate the positive anomalies associated with the storm, but tropical cyclones also create negative anomalies nearby through compensating subsidence. This subsidence manifests itself as the moat of negative rainfall anomalies surrounding each storm's core.

Figure $3 \mathrm{~d}$ displays the modified precipitation field with the tropical cyclones removed. The tropical cyclone-related anomalies (Fig. 3c) are subtracted from the original data (Fig. 3a) to produce this modified rainfall. The precipitation in the cores of the tropical cyclones (within $500 \mathrm{~km}$ ) has been greatly reduced, while the shield of light rainfall $\left(<10 \mathrm{~mm} \mathrm{day}^{-1}\right)$ has been expanded around the storms. Some remaining features, such as the cyclonically curved band of rainfall to the north of Borneo, could be attributable to the tropical cyclones. Without analyzing dynamical fields, it would be impossible to determine whether this feature is associated with the tropical depression. The rainfall rates in this band are weaker than those found in the cores of the storms, so they should exert a smaller influence on the filtered fields. The appendix shows that doubling the radius at half-maximum $(R)$ of the tropical cyclone-related anomalies has a negligible impact on the results of this paper. 
Figures $4 \mathrm{a}$ and $5 \mathrm{a}$ show the warm season mean and variance, respectively, of the original precipitation data. Both fields are largest in a band that extends northwestward from the inter-tropical convergence zone (ITCZ) in the central Pacific. The striking similarity between the patterns of the mean and variance is typical for convective precipitation, which is highly variable by nature. This convection provides a preferred region for cyclogenesis although the storms (black dots) generally develop on the northern side of the convective maximum.

The general pattern of the precipitation mean and variance remains similar following the removal of the tropical cyclone signals (Figs. 4b, 5b). The most prominent difference is the weakened rainfall variance to the east of the Philippines. The ITCZ still dominates, but tropical cyclones seem to play an important role in extending the convective maximum to the northwest. This pattern is consistent with Rodgers et al. (2000) who found that the maximum tropical cyclone-related rainfall was $5^{\circ}-10^{\circ}$ latitude poleward of the maximum total rainfall.

The mean and variance of the tropical cyclone-related rainfall anomalies are shown in Figs. 4c and 5c, respectively. The tropical cyclones contribute strongly to the mean and variance of rainfall in the northwestern portion of the basin where the concentration of storms is greatest. In this region, the tropical cyclones are responsible for more than $20 \%$ of the mean rainfall, and up to $50 \%$ of its variance (Figs. $4 d, 5 d$ ).

As illustrated by Fig. 2, the precipitation variance associated with tropical cyclones can contaminate the filtered fields that are frequently used to identify equatorial waves. Figure 6a quantifies the contamination by showing the wavenumber-frequency spectra for the tropical cyclone-related anomalies. This spectrum is calculated in the same 
manner as Fig. 1a but only for those anomalies that have been attributed to tropical cyclones.

Upon first glance, Fig. 6a suggests a serious concern for previous climatologies of equatorial waves (e.g. Wheeler and Kiladis 1999): Tropical cyclones produce significant power in nearly all of the equatorial wave filter bands. However, the contours in Fig. 6a, which represent the base-10 logarithm of the variance, are smaller than in Fig. 1a. To illustrate the difference in magnitude, Fig. $6 \mathrm{~b}$ shows the percentage of the total power that is associated with tropical cyclone-related anomalies. The strongest tropical cyclonerelated power falls within the MJO filter band (Fig. 6a), but the MJO power is much stronger in the total spectrum (Fig. 1a). Tropical cyclones contribute less than $6 \%$ of this peak (Fig. 6b). If the MJO were simply a manifestation of tropical cyclones, then we would expect this percentage to be much larger. A more likely explanation of the MJO peak in Fig. 6a could be that the MJO's modulation of tropical cyclones is strong enough to appear in this type of analysis.

In addition to the MJO peak, a portion of the tropical cyclone-related variance propagates westward at roughly $5 \mathrm{~m} \mathrm{~s}^{-1}$ (Fig. 6a, thick dashed line). Tropical cyclones generally move westward at low latitudes, so this signal may be expected. This variance falls within the ER filter band and the lower frequency portions of the MRG and TD-type bands, but tropical cyclones only contribute a small percentage of the total variance within any filter band (Fig. 6b).

The largest contribution by tropical cyclones to any portion of the spectrum is only $17 \%$, and it is generally much smaller within the equatorial wave filter bands (Fig. $6 \mathrm{~b})$. Figure 6 is calculated using a radius at half maximum of $500 \mathrm{~km}$ for the tropical 
cyclone-related anomalies. Even if this radius is doubled, the maximum contribution from the tropical cyclones to any portion of the spectrum is still only $22 \%$ (not shown). These percentages are small in part because tropical cyclones are relatively uncommon, especially at low latitudes. The spectrum is calculated from the equator to $15^{\circ} \mathrm{N}$, but the tropical cyclones primarily produce rainfall variance poleward of $10^{\circ} \mathrm{N}$ (Fig. $5 \mathrm{c}$ ).

The low percentages in Fig. $6 \mathrm{~b}$ suggest that tropical cyclone contamination probably did not overly affect previous climatologies of equatorial waves (e.g., Wheeler and Kiladis 1999; Yang et al. 2003; Roundy and Frank 2004). However, Fig. 2 demonstrates that tropical cyclones can significantly alter the filtered fields at their own genesis location. This contamination must be accounted for in order to examine the influences of equatorial waves on tropical cyclones. The present study will mitigate these effects by removing the tropical cyclone-related anomalies before filtering. This removal is applied in all basins and to all tropical cyclone positions that meet the minimum intensity of $13 \mathrm{~m} \mathrm{~s}^{-1}$. Removing the anomalies associated with all tropical cyclones is important because Fig. 2 demonstrates that a storm can contaminate filtered fields at large distances in space and time.

\section{Attributing tropical cyclones to equatorial waves}

Figure 7 uses the genesis of Typhoon Lingling to illustrate the attribution method. The shading in Fig. 7 depicts the unfiltered rainfall rates following the removal of the tropical cyclone-related anomalies. In this example, the precipitation data are then filtered for MRG waves, and the resulting MRG anomalies are contoured in red. The MRG filter produces an anomaly of $3.97 \mathrm{~mm}$ day ${ }^{-1}$ in the $1^{\circ}$ grid box containing Lingling's genesis. 
This anomaly is positive, so the MRG waves appear to contribute favorably to genesis. It is unclear whether that anomaly is sufficient to attribute Lingling's formation to these waves. An attribution threshold must be selected against which this anomaly will be compared.

To aid this selection, Fig. 8 shows the percentage of all warm season western North Pacific data points that exceed a given threshold. Only 145 tropical cyclones formed amongst the $2.6 \times 10^{6}$ total data points, so Fig. 8 essentially represents nongenesis points. The curves in this figure can also be thought of as the inverted cumulative density functions for each wave type. As expected with Fourier filtering, approximately half of the filtered data are positive. This fraction decreases for higher thresholds, and less than $4 \%$ of the data exceed $6 \mathrm{~mm} \mathrm{day}^{-1}$.

Figure 9 reveals the results of the attribution measures. It shows the percentage of the 145 warm season western North Pacific storms that developed while the filtered anomaly at the nearest grid point exceeded a given threshold. These percentages can sum to more than $100 \%$ because a given storm may be attributed to more than one wave. The black line indicates the percentage of storms for which none of the five equatorial wave types met the threshold. The percentage of genesis points exceeding a given threshold (Fig. 9) is almost always greater than the percentage of total points exceeding that same threshold (Fig. 8). Within the range of thresholds shown, the only exception is the MJO for thresholds greater than $5.8 \mathrm{~mm} \mathrm{day}^{-1}$. Even though Figs. 8 and 9 are calculated after removing the tropical cyclone-related signals, the genesis points are still associated with greater rainfall anomalies than the non-genesis points. 
TD-type disturbances produced positive rainfall anomalies for $79 \%$ of the 145 tropical cyclone formations (Fig. 9). The percentages are less for other equatorial waves, but each wave type generated positive anomalies for at least $62 \%$ of the storms. Liebmann et al. (1994) and Frank and Roundy (2006) found similar results using OLR data even though these past studies did not remove the tropical cyclone-related anomalies. Every tropical cyclone formed when at least one of the five equatorial waves yielded a positive anomaly, and $16 \%$ of the storms formed when all five were positive (not shown). For attribution, the threshold needs to discriminate between wave types that are active and those that are not. A small positive anomaly could be the result of "noise" projecting onto an equatorial wave's filter band.

As the threshold increases, the number of storms attributed to each wave naturally decreases. If $6 \mathrm{~mm} \mathrm{day}^{-1}$ were chosen as the threshold, then $68 \%$ of the storms would have no equatorial wave precursor. In addition, TD-type disturbances would have only supported $19 \%$ of the tropical cyclone formations with lesser percentages for the other waves. Ritchie and Holland (1999) and Fu et al. (2007) each found that half of western North Pacific tropical cyclones were associated with TD-type disturbances, so the 6-mm day ${ }^{-1}$ threshold is too strict to be consistent with past research.

We chose $3 \mathrm{~mm} \mathrm{day}^{-1}$ for the threshold for two primary reasons. First, this threshold is relatively strict. It is greater than $87 \%-95 \%$ of all filtered data points depending on the particular equatorial wave type (Fig. 8; the $90^{\text {th }}$ percentile is indicated by the horizontal dotted line). Second, this threshold produces results that are consistent with previous synoptic studies. About one-half (51\%) of the 145 western North Pacific storms are attributed to TD-type disturbances with this threshold (Fig. 9), which is 
consistent with Ritchie and Holland (1999) and Fu et al. (2007). In addition, 29\% of storms are attributed to ER waves, $26 \%$ to MRG waves, $23 \%$ to Kelvin waves, $13 \%$ to the MJO, and $19 \%$ are not attributed to any wave.

Table 1 shows the number of tropical cyclones attributed to multiple equatorial wave types using the $3-\mathrm{mm}$ day $^{-1}$ threshold. Only 18 of the 145 storms are attributed to three or more equatorial waves. Unlike the zero threshold, no storms are attributed to all five wave types. Because more than two-thirds (99 of 145) of the storms are attributed to only one or two wave types, these attributions seem to distinguish meaningfully between the wave types.

Table 2 shows how many tropical cyclones are attributed to each combination of two equatorial wave types. The small number of storms that have three or four equatorial wave precursors are counted under each combination of two of those wave types. For example, a storm attributed to ER waves, MRG waves, and TD-type disturbances would be counted as ER-MRG, ER-TD, and MRG-TD.

Approximately one-half (74 of 145) of all western North Pacific tropical cyclones are attributed to TD-type disturbances (Table 1). Just by chance, we might expect that about one-half of the storms attributed to any other equatorial wave would also be attributed to TD-type disturbances. Table 2 shows that this is indeed the case for ER waves (21 of 42) and the MJO (8 of 19). Only one-third (11 of 33) of the storms attributed to Kelvin waves are also attributed to TD-type disturbances. Kelvin waves and TD-type disturbances move in opposite directions with relatively short periods (generally 2.5-9 days; Fig 1). It is possible that their positive rainfall anomalies do not coincide for long enough to jointly support cyclogenesis. 
Nearly two-thirds (24 of 37) of the storms attributed to MRG waves are also attributed to TD-type disturbances. Both wave types move westward with similar periods. This large fraction could indicate that the filters are not adequately separating the two wave types. If this is the case, then the same disturbance could appear simultaneously in both filters. The overlap could be physically meaningful, however. Dickinson and Molinari (2002) showed that tropical cyclogenesis could occur when MRG waves transitioned to TD-type structures. These transitioning systems could explain the relatively large fraction of storms attributed to both wave types.

Figures 10a-e show the genesis locations of the storms attributed to each equatorial wave with the $3-\mathrm{mm} \mathrm{day}^{-1}$ threshold. These locations are overlaid on the warm season variance of the filtered precipitation for each wave type, which are qualitatively similar to those found by Roundy and Frank (2004). The primary difference is that the variance maxima generally do not extend as far poleward in Fig. 10 because of the removal of the tropical cyclone-related anomalies.

The pattern of TD-type variance (Fig. 10a) resembles that of the total variance with the tropical cyclones removed (Fig. 5b), which is consistent with previous studies that have noted the prominence of TD-type disturbances in the western North Pacific (e.g., Reed and Recker 1971; Lau and Lau 1990; Takayabu and Nitta 1993; Dunkerton and Baldwin 1995; Chang et al. 1996). By contrast, the MRG wave variance peaks in the central North Pacific (Fig. 10b). These patterns are consistent with previous studies that have shown MRG waves transitioning to TD-type structures in the western North Pacific (Sobel and Bretherton 1999; Dickinson and Molinari 2002; Aiyyer and Molinari 2003; Fu et al. 2007). 
The MJO variance (Fig. 10e) is concentrated in the western North Pacific, while the Kelvin wave variance (Fig. 10d) is stronger in the central North Pacific ITCZ. This pattern is consistent with previous studies (e.g., Hendon and Salby 1994; Straub and Kiladis 2003) that observed Kelvin waves radiating to the east of the MJO as it dissipates.

The tropical cyclones attributed to the MRG waves typically formed farther equatorward than other storms. The mean genesis latitude for all western North Pacific tropical cyclones from the equator to $20^{\circ} \mathrm{N}$ is $13.4^{\circ} \mathrm{N}$ while the mean for the MRG-related storms is $11.8^{\circ} \mathrm{N}$. This difference is significant at the $95 \%$ level using either a Student's $t$ test or a bootstrap test. Similarly, the mean latitude for storms attributed to the MJO is $10.4^{\circ} \mathrm{N}$, which is also significantly equatorward of the overall mean.

Figure 10f shows the genesis locations of storms for which none of the equatorial waves met the 3-mm day ${ }^{-1}$ threshold. Only one tropical cyclone developed equatorward of $10^{\circ} \mathrm{N}$ without an equatorial wave precursor, and the mean genesis latitude for these storms is $15.4^{\circ} \mathrm{N}$. This mean latitude is significantly farther north than that for all western North Pacific tropical cyclones. Not surprisingly, these results indicate that equatorial waves are most likely to affect cyclogenesis close to the equator.

\section{Discussion}

Previous studies (e.g., Liebmann et al. 1994; Bessafi and Wheeler 2006; Frank and Roundy 2006) have demonstrated that equatorial waves can significantly modulate tropical cyclogenesis. The current study has attempted to determine what fraction of tropical cyclone formations can be directly attributed to each equatorial wave type. Tropical cyclones themselves contribute significantly to the convective variability in the 
western North Pacific (Fig. 5), and tropical cyclone-related variance can contaminate equatorial wave-filtered fields. This study isolates the tropical cyclone-related anomalies to quantify and mitigate this effect.

\section{a. Tropical cyclone signals}

Tropical cyclones can produce intense rainfall at rates greater than $100 \mathrm{~mm} \mathrm{day}^{-1}$ (Fig. 3). Such rainfall rates represent the $99^{\text {th }}$ percentile of the precipitation data for the western North Pacific warm season 1998-2007 (not shown). The heavy precipitation associated with tropical cyclones accounts for more than $20 \%$ of the total warm season mean rainfall in some portions the western North Pacific (Fig. 4d). Tropical cyclones can also contribute as much as $50 \%$ of the rainfall variance (Fig. $5 \mathrm{~d}$ ). Consistent with previous studies (e.g., Rodgers et al 2000; Kubota and Wang 2009), tropical cyclones exert their greatest influence on rainfall near Taiwan and to the east of the Philippines (Figs. 4 and 5). The tropical cyclone-related rainfall also occurs poleward of the nontropical cyclone rainfall as in Rodgers et al. (2000). This pattern suggests that tropical cyclones extend the convection poleward from the ITCZ.

Much of the tropical cyclone-related rainfall variance falls within equatorial wave filter bands (Fig. 6a). The bands for ER waves, MRG waves, and TD-type disturbances are particularly vulnerable to contamination from tropical cyclones. These waves move westward at speeds that might be typical for low-latitude storms. The largest spectral peak associated with tropical cyclones falls within the MJO band. Tropical cyclones only contribute $6 \%$ of the total MJO spectral peak, however, so this signal is probably due to the modulation of tropical cyclones by the MJO. Tropical cyclone-related signals account 
less than $17 \%$ of the total power in any portion of the spectrum and less than $12 \%$ within the equatorial wave filter bands (Fig. 6b). These percentages are small in part because tropical cyclones are relatively uncommon, especially at the low latitudes $\left(\leq 15^{\circ}\right)$ for which equatorial wave spectra are typically calculated.

Previous studies of equatorial waves have generally ignored tropical cyclonerelated signals. As described above, tropical cyclones do not overly affect the broad climatology of equatorial waves (e.g., Wheeler and Kiladis 1999; Yang et al. 2003; Roundy and Frank 2004). However, tropical cyclones can significantly alter the wavefiltered fields at their own genesis locations (Fig. 2). This contamination needs to be addressed in order to examine the role of equatorial waves in cyclogenesis. The current study achieves this by removing the tropical cyclone-related signals before filtering.

\section{b. Equatorial wave attributions}

After the tropical cyclone signals were removed, the remaining rainfall data were filtered for each equatorial wave type. Tropical cyclogenesis was attributed to an equatorial wave if the filtered anomaly exceeded a threshold value in the $1^{\circ}$ latitudelongitude box containing the genesis location. The attributions were sensitive to the choice of threshold (Fig. 9), so this selection was an important component of the research.

Simply requiring the rainfall anomalies to be positive (equivalent to a zero threshold) would attribute $16 \%$ of the western North Pacific tropical cyclones to all five equatorial wave types, which is not physically meaningful. This low threshold cannot discriminate between those waves that are active and those that are not. Setting the 
threshold too high also yields unreasonable results. For a threshold of $6 \mathrm{~mm}^{\mathrm{day}}{ }^{-1}, 68 \%$ of the storms would have no wave precursor. These results would be inconsistent with Ritchie and Holland (1999) and Fu et al. (2007) who each attribute about half of tropical cyclone formations to TD-type disturbances alone.

Between these extremes, $3 \mathrm{~mm}^{-1 a y}{ }^{-1}$ was chosen as the threshold for this study. This value is near the $90^{\text {th }}$ percentile of all western North Pacific data for each equatorial wave type (Fig. 8). It is also strict enough to distinguish between wave types because only $12 \%$ of tropical cyclones are attributed to more than two wave types (Table 1 ). At the same time, this threshold is low enough that $81 \%$ of the storms are attributed to at least one wave type. This threshold also attributed $51 \%$ of the tropical cyclone formations to TD-type disturbances, which is supported by Ritchie and Holland (1999) and Fu et al. (2007). The 3-mm day ${ }^{-1}$ threshold is relatively strict, and it yields attributions that are consistent with previous research. ER waves, MRG waves, and Kelvin waves were each associated with $20 \%-30 \%$ of tropical cyclone formations with this threshold, while only $13 \%$ of storms were attributed to the MJO.

Contrary to these results, past studies (e.g., Liebmann et al. 1994; Maloney and Hartmann 2000; Hall et al. 2001; Bessafi and Wheeler 2006; Kim et al. 2008; Camargo et al. 2009) have shown that the MJO can produce significant modulations of tropical cyclogenesis. This disparity with past research is not sensitive to the threshold selection. For any threshold greater than $1.2 \mathrm{~mm} \mathrm{day}^{-1}$, fewer tropical cyclone formations are attributed to the MJO than any other wave type. The disagreement could stem from the differences between modulation and attribution. The MJO is a planetary scale feature that can produce a large envelope of favorable conditions. The size of this envelope creates 
the basin-wide modulations of cyclogenesis found by past studies. By contrast, our method for attribution examined a more localized effect, specifically the wave-related anomaly at the actual genesis location. The MJO alone might not be able to dictate when and where a storm will form within the broad envelope of favorable conditions, which would explain why so few storms were directly attributed to it in Fig. 9.

About one-fifth of the tropical cyclones were not attributed to any equatorial wave using the 3-mm day ${ }^{-1}$ threshold. In the absence of an equatorial wave precursor, these storms could have been the product of upper-level trough interactions (Sadler 1976), tropical transition (Davis and Bosart 2001), or localized mesoscale convective systems (MCSs) within the monsoon trough (Ritchie and Holland 1999). The storms with no equatorial wave precursor typically originated farther poleward than other storms (Fig. 10f). Upper-level troughs and tropical transition are more common at higher latitudes, which would be consistent with this pattern.

The present study has examined the attribution of tropical cyclones to equatorial waves in the western North Pacific. These attributions were based solely on the rainfall anomalies at the genesis location. This method is consistent with previous studies using OLR (e.g., Liebmann et al. 1994; Dickinson and Molinari 2002; Bessafi and Wheeler 2006; Frank and Roundy 2006; Molinari et al. 2007; Schreck and Molinari 2009) that have shown convection to be one of the primary ways in which equatorial waves influence cyclogenesis. For completeness, future attributions should also include dynamical fields. Low-level vorticity may be the most important of these fields, but equatorial waves can also modulate divergence and vertical wind shear. Attribution criteria should be developed to incorporate these influences along with the convective 
anomalies used in this study. In addition, the attributions should be extended to other basins to quantify the importance of equatorial waves for cyclogenesis in those regions.

The results of this and future attribution studies should be relevant to forecasters. Equatorial waves can be identified and forecasted in real-time with statistical methods (Wheeler and Weickmann 2001; Roundy and Schreck 2009). Such forecasts could be combined with the attribution information in Fig. 9 to indicate where and when an equatorial wave might favor cyclogenesis. This approach would be complimentary to current regression models that forecast cyclogenesis based on equatorial waves (Frank and Roundy 2006; Leroy and Wheeler 2008).

Acknowledgments. This research has benefited greatly from conversations with Anantha Aiyyer, Paul Roundy, Adam Sobel, Chris Thorncroft, and Lance Bosart. We obtained the TMPA data from the NASA Goddard Distributed Active Archive Center (online at http://disc.sci.gsfc.nasa.gov/data/datapool/TRMM/). We are grateful to Dave Vollaro for his assistance in obtaining and interpolating this data. This work was supported by NSF Grant ATM0839991 and NASA Precipitation Measuring Mission Grant NNX07AD45G.

\section{APPENDIX}

\section{Sensitivity of attributions to radius of tropical cyclone removal}

In this study, the anomalies associated with each tropical cyclone were removed. This procedure uses a Gaussian function (Eq. 1) centered on the storm to separate the anomalies associated with the storm from those associated with the larger scale 
environment (including equatorial waves). Anomalies at a radius $R=500 \mathrm{~km}$ were considered half associated with each. The remaining data were then filtered to determine which tropical cyclones were influenced by equatorial waves.

Figure A1 shows the percentage of the 145 western North Pacific storms attributed to each equatorial wave using five radii at half maximum $(R)$ for the removal: 0 $\mathrm{km}$ (no removal), $250 \mathrm{~km}, 500 \mathrm{~km}, 750 \mathrm{~km}$, and $1000 \mathrm{~km}$. This figure is analogous to Fig. 9 that showed the sensitivity to the attribution threshold. The attributions in Fig. A1 use a threshold value of $3 \mathrm{~mm} \mathrm{day}^{-1}$, but other thresholds produce similar results (not shown).

Substantially fewer storms are attributed to each equatorial wave for a removal radius of $500 \mathrm{~km}$ compared with no removal (Fig. A1). For example, the percentage attributed to TD-type disturbances decreases from $76 \%$ to $51 \%$ (dark red curve). Conversely, the percentage of storms not attributed to any equatorial wave increases from $5 \%$ to $19 \%$ (black curve). These differences illustrate the influences of the tropical cyclone-related signals and the need to remove them.

Figure A1 also demonstrates that the attributions are largely unaffected by expanding $R$ beyond $500 \mathrm{~km}$. For example, doubling the radius to $1000 \mathrm{~km}$ only decreases the percentage of storms attributed to ER waves from 29\% to 23\% (orange curve). The differences are even smaller for the other equatorial waves. Some tropical cyclone-related signals might be left behind by the removal for $R=500 \mathrm{~km}$ (Fig. 3d), but Fig. A1 suggests that these remaining signals have a negligible effect on the attribution results. 


\section{REFERENCES}

Aiyyer, A., and J. Molinari, 2003: Evolution of mixed Rossby-gravity waves in idealized MJO environments. J. Atmos. Sci., 60, 2837-2855.

Bessafi, M., and M. C. Wheeler, 2006: Modulation of south Indian Ocean tropical cyclones by the Madden-Julian oscillation and convectively coupled equatorial waves. Mon. Wea. Rev., 134, 638-656.

Camargo, S. J., M. C. Wheeler, and A. H. Sobel, 2009: Diagnosis of the MJO modulation of tropical cyclogenesis using an empirical index. J. Atmos. Sci., in press.

Chang, C.-P., J. M. Chen, P. A. Harr, and L. E. Carr, 1996: Northwestward-propagating wave patterns over the tropical Western North Pacific during Summer. Mon. Wea. Rev., 124, 2245-2266.

Cho, H.-K., K. P. Bowman, and G. R. North, 2004: Equatorial waves including the Madden-Julian oscillation in TRMM rainfall and OLR data. J. Climate, 17, $4387-4406$

Davis, C. A., and L. F. Bosart, 2001: Numerical simulations of the genesis of Hurricane Diana (1984). Part I: control simulation. Mon. Wea. Rev., 59, 2183-2196.

Dickinson, M. J., and J. Molinari, 2002: Mixed Rossby-gravity waves and western Pacific tropical cyclogenesis. Part I: Synoptic evolution. J. Atmos. Sci., 59, 21832196.

Dunkerton, T. J., and M. P. Baldwin, 1995: Observation of 3-6-day meridional wind oscillations over the tropical Pacific, 1973-1992: Horizontal Structure and Propagation. J. Atmos. Sci., 52, 1585-1601. 
Frank, W. M., and P. E. Roundy, 2006: The role of tropical waves in tropical cyclogenesis. Mon. Wea. Rev., 134, 2397-2417.

Fu, B., T. Li, M. S. Peng, and F. Weng, 2007: Analysis of tropical cyclogenesis in the western North Pacific for 2000 and 2001. Wea. Forecasting, 22, 763-780.

Hall, J. D., A. D. Matthews, D. J. Karoly, 2001: The modulation of tropical cyclone activity in the Australian region by the Madden-Julian oscillation. Mon. Wea. Rev., 129, 2970-2982.

Hendon, H. H. and M. L. Salby, 1994: The life cycle of the Madden-Julian oscillation. J. Atmos. Sci., 51, 2225-2237.

Hsu, H.-H., C.-H. Hung, A.-K. Lo, C.-C. Wu, and C.-W. Hung, 2008: Influence of tropical cyclones on the estimation of climate variability in the tropical western North Pacific. J. Climate, 21, 2960-2975.

Huffman, G. J., and Coauthors, 2007: The TRMM multiscale precipitation analysis (TMPA): Quasi-global, multiyear, combined-sensor precipitation estimates at fine scales. J. Hydrometor., 8, 38-55.

Kiladis, G. N., C. D. Thorncroft, and N. M. J. Hall, 2006: Three-dimensional structure and dynamics of African easterly waves. Part I: Observations. J. Atmos. Sci., 63, $2212-2230$.

Kiladis, G. N., M. C. Wheeler, P. T. Haertel, K. H. Straub, and P. E. Roundy, 2009: Convectively coupled equatorial waves. Rev. Geophys., 47, RG2003, doi:10.1029/2008RG000266. 
Kim, J.-H., C.-H. Ho, H.-S. Kim, C.-H. Sui, S. K. Park, 2008: Systematic variation of summertime tropical cyclone activity in the western North Pacific in relation to the Madden-Julian Oscillation. J. Climate, 21, 1171-1191.

Knapp, K. R., M. C. Kruk, D. H. Levinson, and E. J. Gibney, 2009: Archive compiles new resource for global tropical cyclone research. Eos, Transactions, $A G U, \mathbf{9 0}$, 10.1029/2009EO060002.

Kubota, H., and B. Wang, 2009: How much do tropical cyclones affect seasonal and interannual rainfall variability over the western North Pacific?. J. Climate, 22, $5495-5510$.

Lau, K.-H., and N.-C. Lau, 1990: Observed structure and propagation characteristics of tropical summertime synoptic scale disturbances. Mon. Wea. Rev., 118, 18881913.

Leroy, A., and M. C. Wheeler, 2008: Statistical prediction of weekly tropical cyclone activity in the Southern Hemisphere. Mon. Wea. Rev., 136, 3637-3654.

Liebmann, B., H. H. Hendon, and J. D. Glick, 1994: The relationship between tropical cyclones of the western Pacific and Indian Oceans and the Madden-Julian oscillation. J. Meteor. Soc. Japan, 72, 401-411.

Maloney, E. D., and D. L. Hartmann, 2000: Modulation of eastern North Pacific hurricanes by the Madden-Julian oscillation. J. Climate, 13, 1451-1460.

Masunaga, H., T. S. L'Ecuyer, and C. D. Kummerow, 2006: The Madden-Julian oscillation recorded in early observations from the tropical rainfall measuring mission (TRMM). J. Atmos. Sci., 63, 2777-2794. 
Molinari, J., K. Lombardo, and D. Vollaro, 2007: Tropical cyclogenesis within an equatorial Rossby wave packet. J. Atmos. Sci., 64, 1301-1317.

Reed, R. J., and E. E. Recker, 1971: Structure and properties of synoptic-scale wave disturbances in the equatorial western Pacific. J. Atmos. Sci., 28, 1117-1133.

Ritchie, E. A., and G. J. Holland, 1999: Large-scale patterns associated with tropical cyclogenesis in the western Pacific. Mon. Wea. Rev., 104, 2027-2043.

Rodgers, E. B., R. F. Adler, and H. F. Pierce, 2000: Contribution of tropical cyclones to the North Pacific climatological rainfall as observed from satellites. J. Appl. Meteor., 39, 1658-1678.

Roundy, P. E., and W. M. Frank, 2004: A climatology of waves in the equatorial region. J. Atmos. Sci., 61, 2105-2132.

Roundy, P. E., and C. J. Schreck III, 2009: A combined wave-number-frequency and time-extended EOF approach for tracking the progress of modes of large-scale organized tropical convection. Quart. J. Roy. Meteor. Soc., 135, 161-173.

Sadler, J. C., 1976: A role of the tropical upper troposphere in early season typhoon development. Mon. Wea. Rev., 104, 1266-1278.

Schreck, C. J. III, and J. Molinari, 2009: A case study of an outbreak of twin tropical cyclones. Mon. Wea. Rev., 137, 836-875.

Serra, Y. L., G. N. Kiladis, M. F. Cronin, 2008: Horizontal and vertical structures of easterly waves in the Pacific ITCZ. J. Atmos. Sci., 65, 1266-1284.

Sobel, A. H., and C. S. Bretherton, 1999: Development of synoptic-scale disturbances over the summertime tropical northwest Pacific. J. Atmos. Sci., 56, 3106-3127. 
Straub, K. H., and G. N. Kiladis, 2003: Extratropical forcing of convectively coupled Kelvin waves during Austral Winter. J. Atmos. Sci., 60, 526-543.

Takayabu, Y. N., and T. Nitta, 1993: 3-5 day-period disturbances coupled with convection over the tropical Pacific Ocean. J. Meteor. Soc. Japan, 71, 221-246.

Wheeler, M., and G. N. Kiladis, 1999: Convectively coupled equatorial waves: Analysis of cloud and temperature in the wavenumber-frequency domain. J. Atmos. Sci., 56, 374-399.

Wheeler, M., and K. M. Weickmann, 2001: Real-time monitoring and prediction of modes of coherent synoptic to intraseasonal tropical variability. Mon. Wea. Rev., 129, 2677-2694.

Yang, G.-Y., B. Hoskins, and J. Slingo, 2003: Convectively coupled equatorial waves: A new methodology for identifying wave structures in observational data. J. Atmos. Sci., 60, 1637-1654.

Zhang, C., 2005: Madden-Julian oscillation. Rev. Geophys., 43, RG2003, doi:10.11029/2004RG000158. 


\section{Figure Captions}

Figure 1. (a) Total wavenumber-frequency power spectrum for warm season TMPA precipitation from the equator to $15^{\circ} \mathrm{N}$. The base-10 logarithm of the power has been plotted. (b) As in (a), but normalized by a red background as in Roundy and Frank (2004). Filter bands are indicated by the cyan boxes. Black lines denote shallow-water dispersion curves for MRG, Kelvin, ER, and inertio-gravity waves with equivalent depths of $8 \mathrm{~m}$ and $90 \mathrm{~m}$.

Figure 2. (a) Time-longitude composite of western North Pacific tropical cyclogenesis.

(b) Time-longitude plot of a prescribed stationary precipitation maximum. Shading indicates unfiltered fields, while filtered anomalies are contoured only at $+1 \mathrm{~mm} \mathrm{day}^{-1}$ for the MJO band (cyan), Kelvin band (blue), ER band (orange), MRG band (red), and TD band (dark red).

Figure 3. Rainfall rates from 0000 UTC 21 August 2000. (a) Latitudinal section along $128^{\circ} \mathrm{E}$ of total rainfall (red), with tropical cyclones removed (blue), climatology (black), and the tropical cyclone weighting function. Maps of (b) total rainfall, (c) tropical cyclone-related anomalies, and (d) modified rainfall rates following the tropical cyclone removal. Black rings indicate the distance to the nearest tropical cyclone every $500 \mathrm{~km}$.

Figure 4. Mean rainfall rate $\left(\mathrm{mm} \mathrm{day}^{-1}\right)$ for May-November 1998-2007: (a) total rainfall, (b) rainfall with the tropical cyclones removed, (c) tropical cyclone-related rainfall, and 
(d) tropical cyclone contribution in percent. Black dots indicate cyclogenesis locations for the same period.

Figure 5. As in Fig. 4, but for rainfall variance $\left[\left(\mathrm{mm} \mathrm{day}^{-1}\right)^{2}\right]$.

Figure 6. (a) As in Fig. 1a, but the spectrum for tropical cyclone-related anomalies. (b) Percent contribution of tropical cyclone-related anomalies to the total spectrum.

Figure 7. Latitude-longitude section of unfiltered rainfall rates following tropical cyclone removal (shading) and MRG-filtered rainfall anomalies (contours) for 0000 UTC 6 Nov 2001. Contours drawn every $1 \mathrm{~mm} \mathrm{day}^{-1}$ with the zero contour omitted and negative contours dashed. The hurricane symbol denotes the genesis location of Typhoon Lingling.

Figure 8. Percentage of all warm season western Pacific data points that exceed a given threshold for the MJO (cyan), Kelvin waves (blue), ER waves (orange), MRG waves (red), or TD-type disturbances (dark red).

Figure 9. Percentage of tropical cyclones that form associated with anomalies that exceed a given threshold for each filter band. Colors as in Fig. 8, except the black curve indicates the percentage of storms for which none of the waves exceeds the threshold. 
Figure 10. Genesis locations for tropical cyclones attributed to (a) TD-type disturbances, (b) MRG waves, (c) ER waves, (d) Kelvin waves, and (e) the MJO overlaid on the warm season variance for the given filter band. (f) Genesis locations for tropical cyclones that were not attributed to any equatorial wave.

Figure A1. Percentages of storms attributed to the MJO (cyan), Kelvin waves (blue), ER waves (orange), MRG waves (red), TD-type disturbances (dark red), or no equatorial waves (black) as functions of the radius at half maximum for the tropical cyclone removal. All attributions use a threshold of $3 \mathrm{~mm} \mathrm{day}^{-1}$. 
Table 1. Number of tropical cyclones attributed to a particular number of equatorial wave types as broken down by wave type.

\begin{tabular}{|c|c|c|c|c|c|c|}
\hline \multicolumn{7}{|c|}{ No. of } \\
\hline Wave & TD-type & MRG & ER & Kelvin & MJO & Total \\
\hline \multicolumn{7}{|l|}{ Types } \\
\hline 0 & - & - & - & - & - & 28 \\
\hline 1 & 27 & 5 & 5 & 10 & 2 & 49 \\
\hline 2 & 32 & 19 & 23 & 14 & 12 & 50 \\
\hline 3 & 13 & 11 & 13 & 7 & 4 & 16 \\
\hline 4 & 2 & 2 & 1 & 2 & 1 & 2 \\
\hline Total & 74 & 37 & 42 & 33 & 19 & 145 \\
\hline
\end{tabular}


Table 2. Number of tropical cyclones attributed to each combination of two equatorial wave types. Storms attributed to three or more wave types are counted for each possible combination of two of those wave types. The table is symmetric about the diagonal.

\begin{tabular}{lccccc}
\hline & TD-type & MRG & ER & Kelvin & MJO \\
\hline TD-type & - & 24 & 21 & 11 & 8 \\
MRG & 24 & - & 14 & 5 & 4 \\
ER & 21 & 14 & - & 12 & 5 \\
Kelvin & 11 & 5 & 12 & - & 6 \\
MJO & 8 & 4 & 5 & 6 & - \\
\hline
\end{tabular}



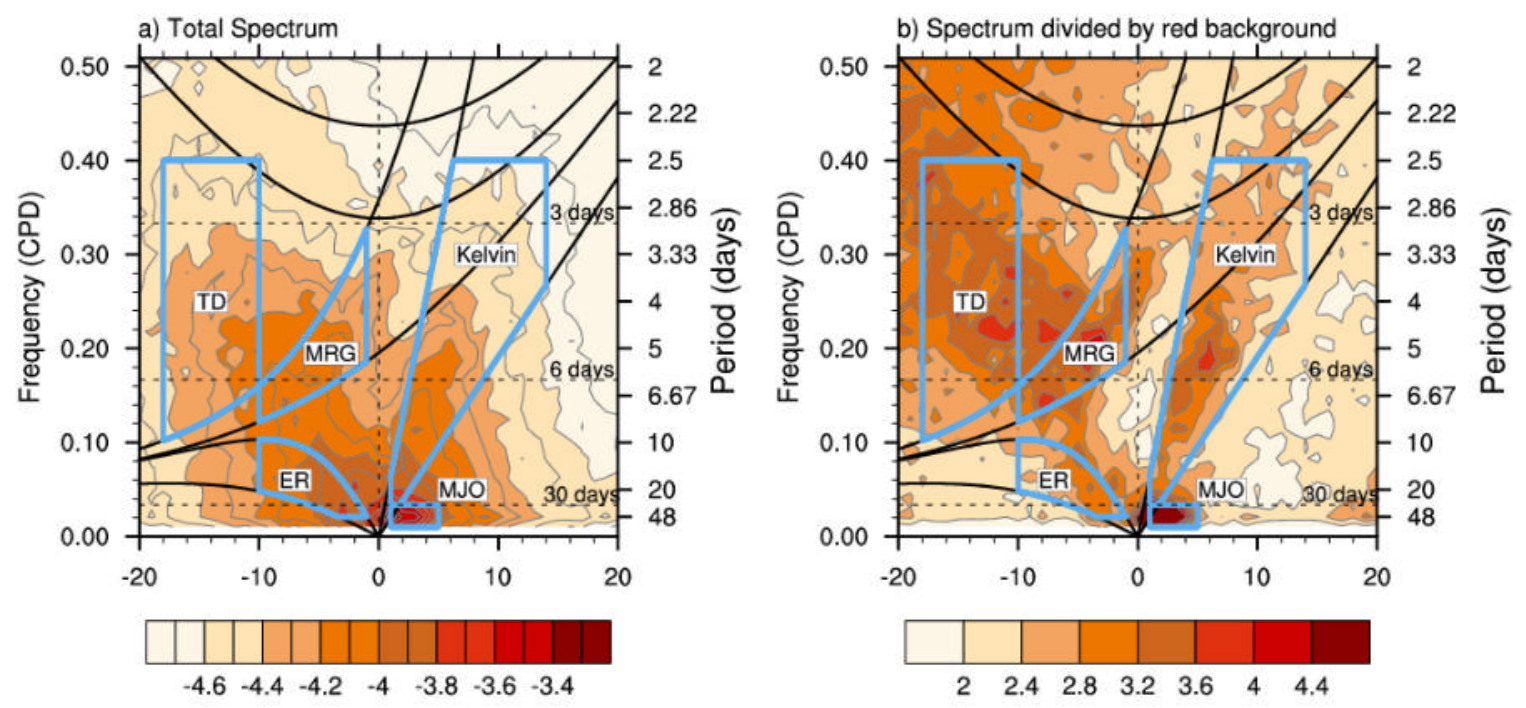

Figure 1. (a) Total wavenumber-frequency power spectrum for warm season precipitation from the equator to $15^{\circ} \mathrm{N}$. The base- 10 logarithm of the power has been plotted. (b) As in (a), but normalized by a red background as in Roundy and Frank (2004). Filter bands are indicated by the cyan boxes. Black lines denote shallow-water dispersion curves for MRG, Kelvin, ER, and inertio-gravity waves with equivalent depths of $8 \mathrm{~m}$ and $90 \mathrm{~m}$. 


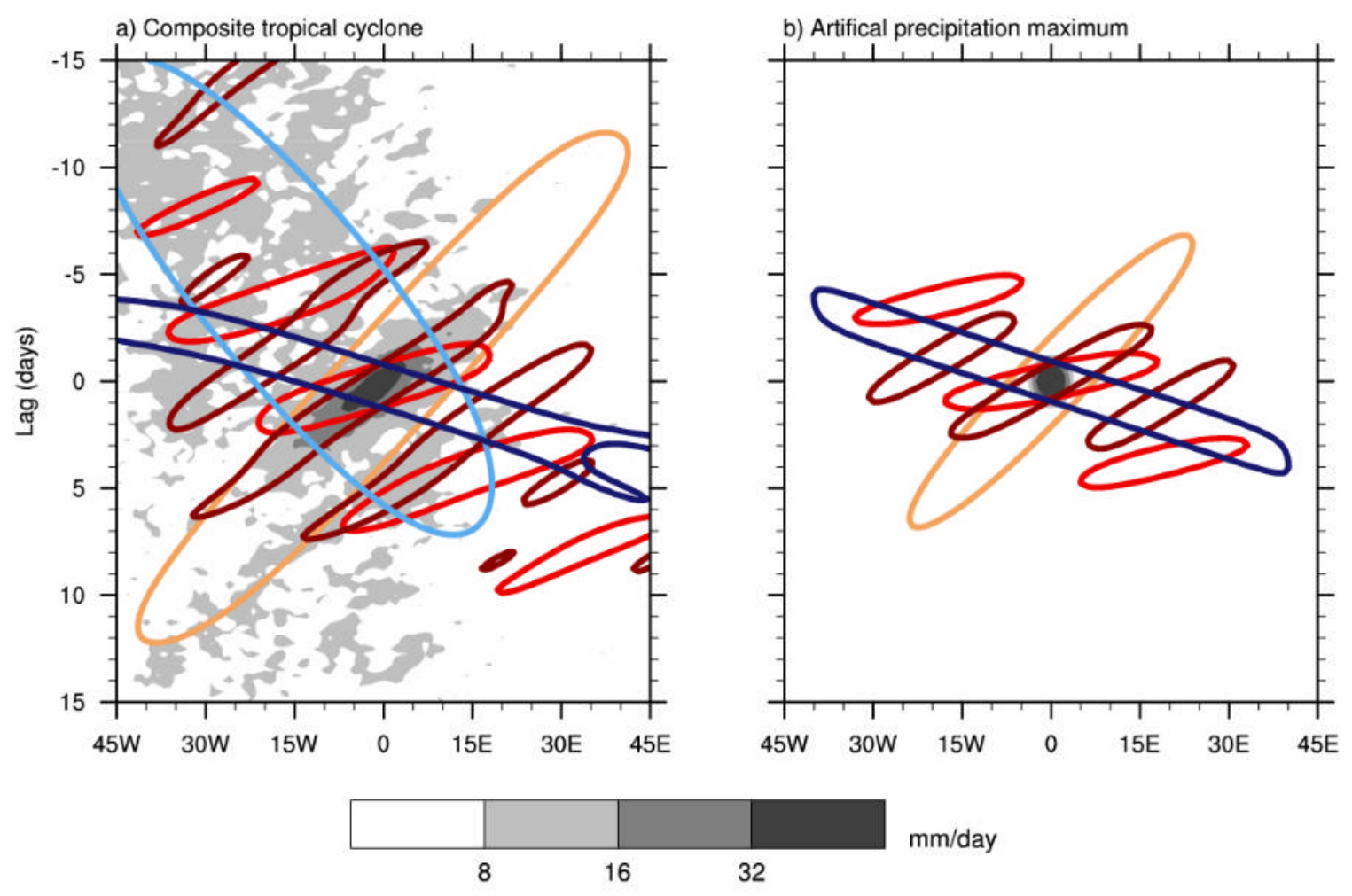

Figure 2. (a) Time-longitude composite of western North Pacific tropical cyclogenesis. (b) Time-longitude plot of a prescribed stationary precipitation maximum. Shading indicates unfiltered fields, while filtered anomalies are contoured only at $+1 \mathrm{~mm}^{\text {day }}{ }^{-1}$ for the MJO band (cyan), Kelvin band (blue), ER band (orange), MRG band (red), and TD band (dark red). 


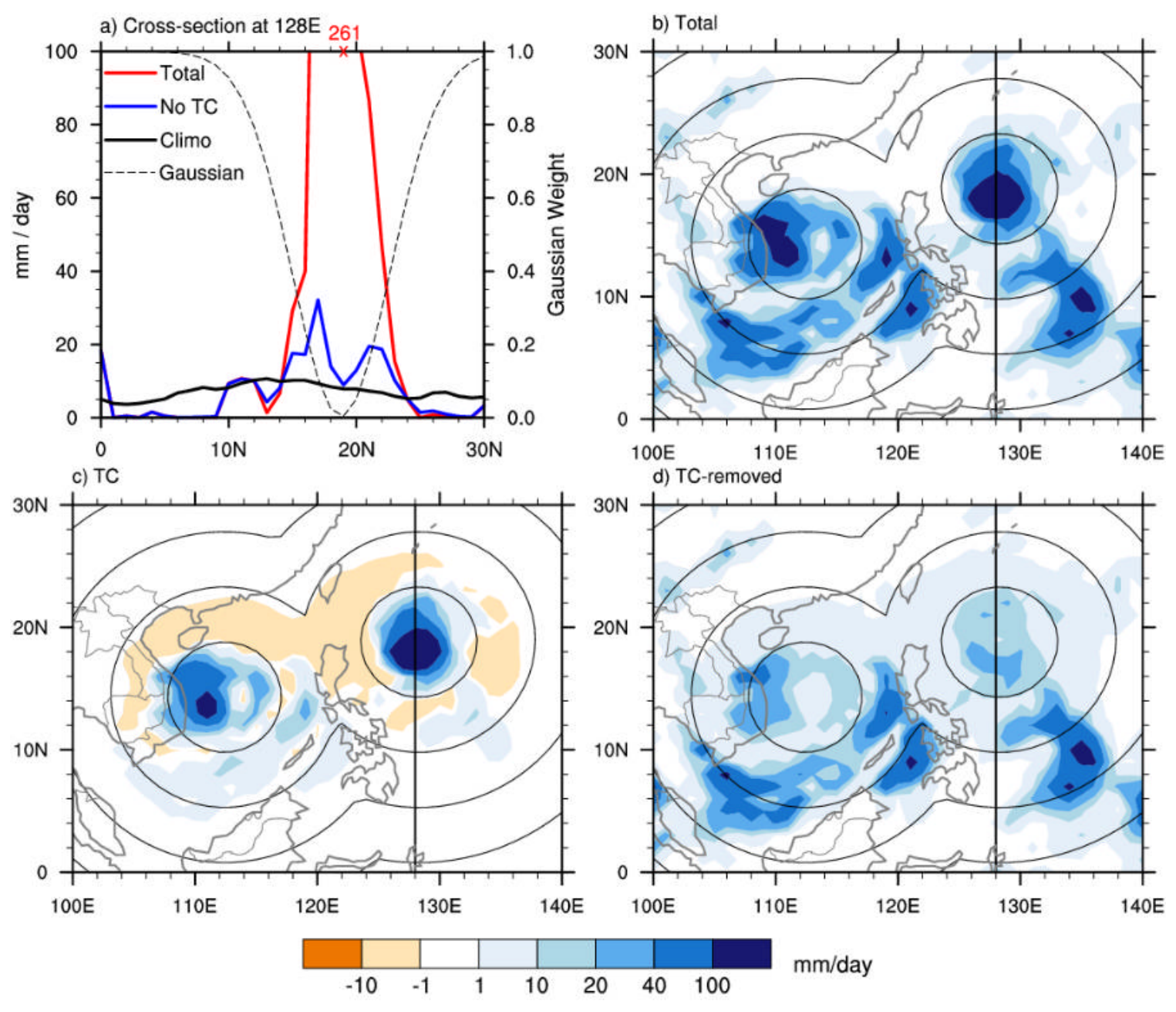

Figure 3. Rainfall rates from 0000 UTC 21 August 2000. (a) Latitudinal section along $128^{\circ} \mathrm{E}$ of total rainfall (red), with tropical cyclones removed (blue), climatology (black), and the tropical cyclone weighting function. Maps of (b) total rainfall, (c) tropical cyclone-related anomalies, and (d) modified rainfall rates following the tropical cyclone removal. Black rings indicate the distance to the nearest tropical cyclone every $500 \mathrm{~km}$. 

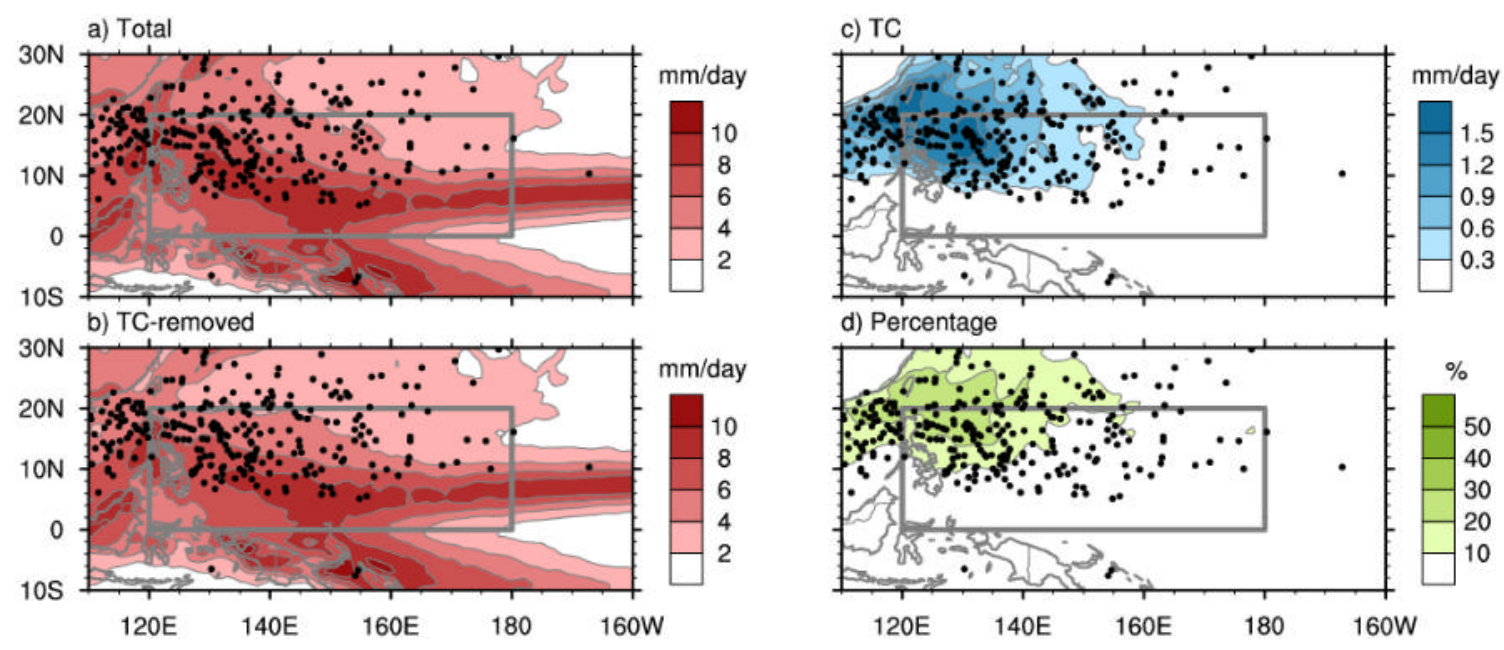

Figure 4. Mean rainfall rate $\left(\mathrm{mm} \mathrm{day}^{-1}\right)$ for May-November 1998-2007: (a) total rainfall, (b) rainfall with the tropical cyclones removed, (c) tropical cyclone-related rainfall, and (d) tropical cyclone contribution in percent. Black dots indicate cyclogenesis locations for the same period. 

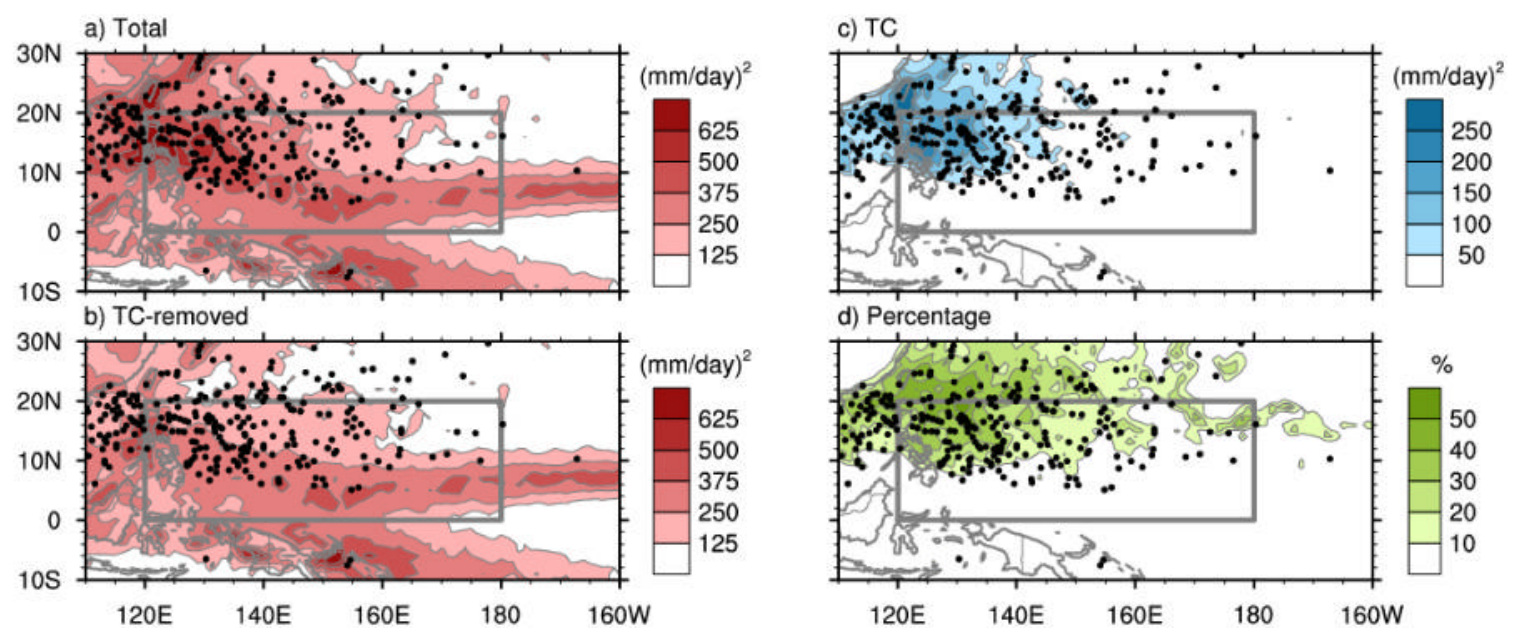

Figure 5. As in Fig. 4, but for rainfall variance $\left[\left(\mathrm{mm} \mathrm{day}^{-1}\right)^{2}\right]$. 

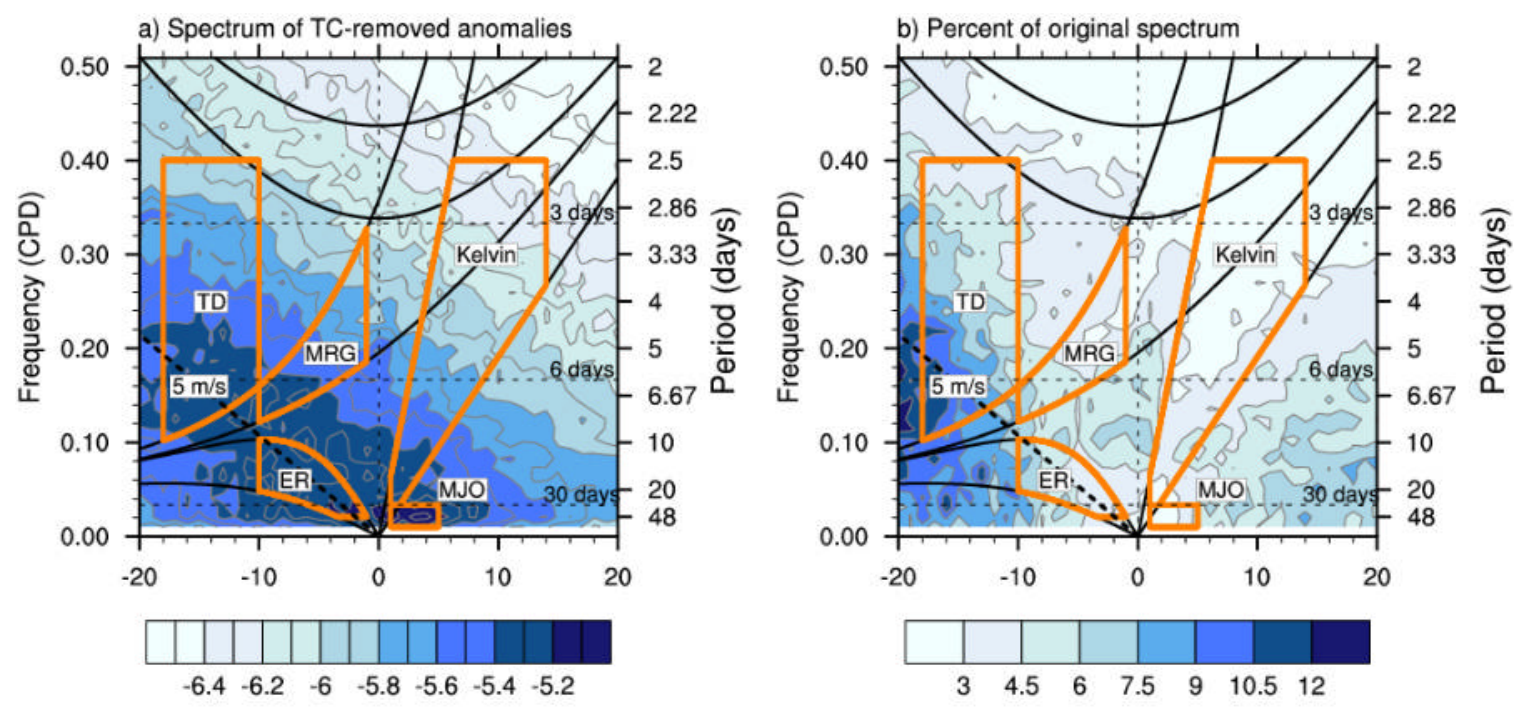

Figure 6. (a) As in Fig. 1a, but the spectrum for tropical cyclone-related anomalies. (b) Percent contribution of tropical cyclone-related anomalies to the total spectrum. 


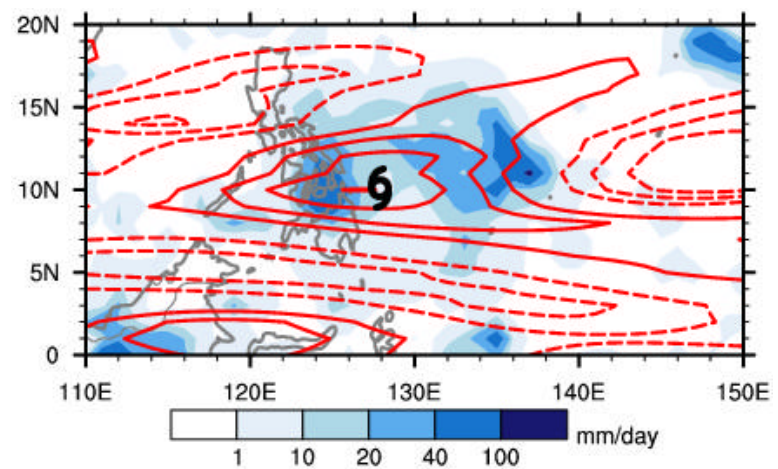

Figure 7. Latitude-longitude section of unfiltered rainfall rates following tropical cyclone removal (shading) and MRG-filtered rainfall anomalies (contours) for 0000 UTC 6 Nov 2001. Contours drawn every $1 \mathrm{~mm}_{\text {day }}{ }^{-1}$ with the zero contour omitted and negative contours dashed. The hurricane symbol denotes the genesis location of Typhoon Lingling. 


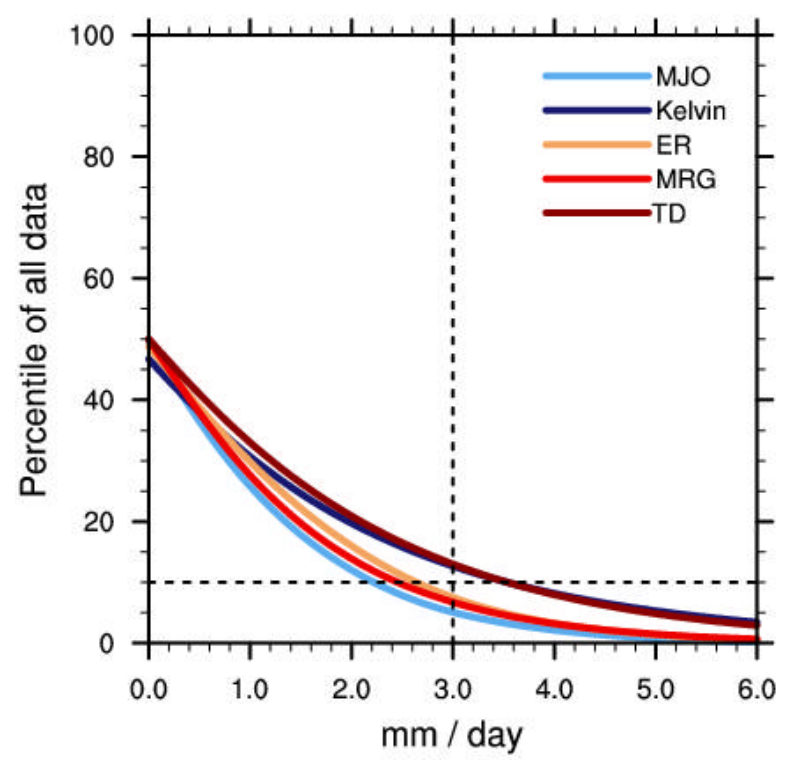

Figure 8. Percentage of all warm season western Pacific data points that exceed a given threshold for the MJO (cyan), Kelvin waves (blue), ER waves (orange), MRG waves (red), or TD-type disturbances (dark red). 


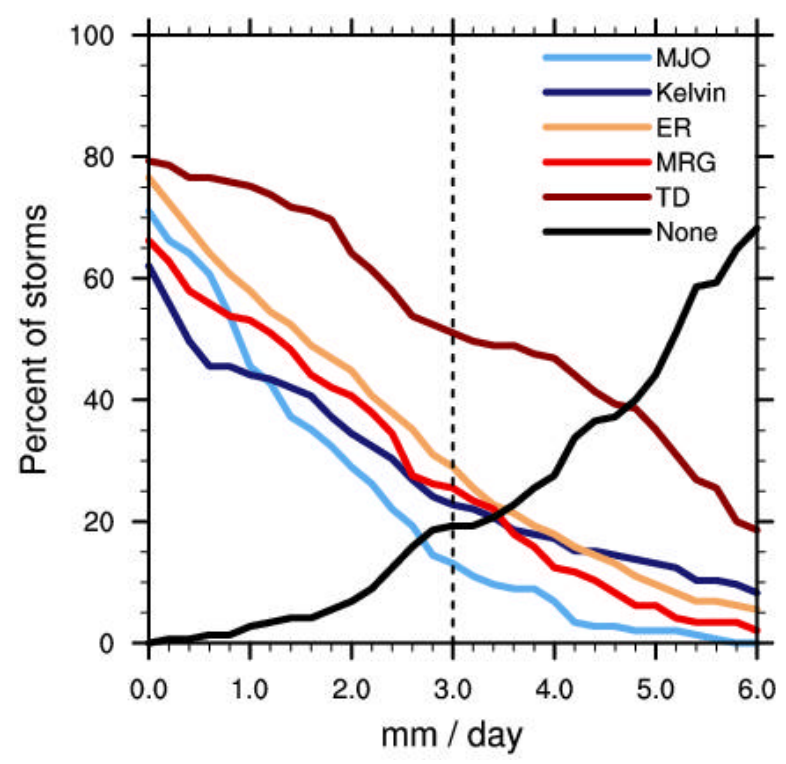

Figure 9. Percentage of tropical cyclones that form associated with anomalies that exceed a given threshold for each filter band. Colors as in Fig. 8, except the black curve indicates the percentage of storms for which none of the waves exceeds the threshold. 

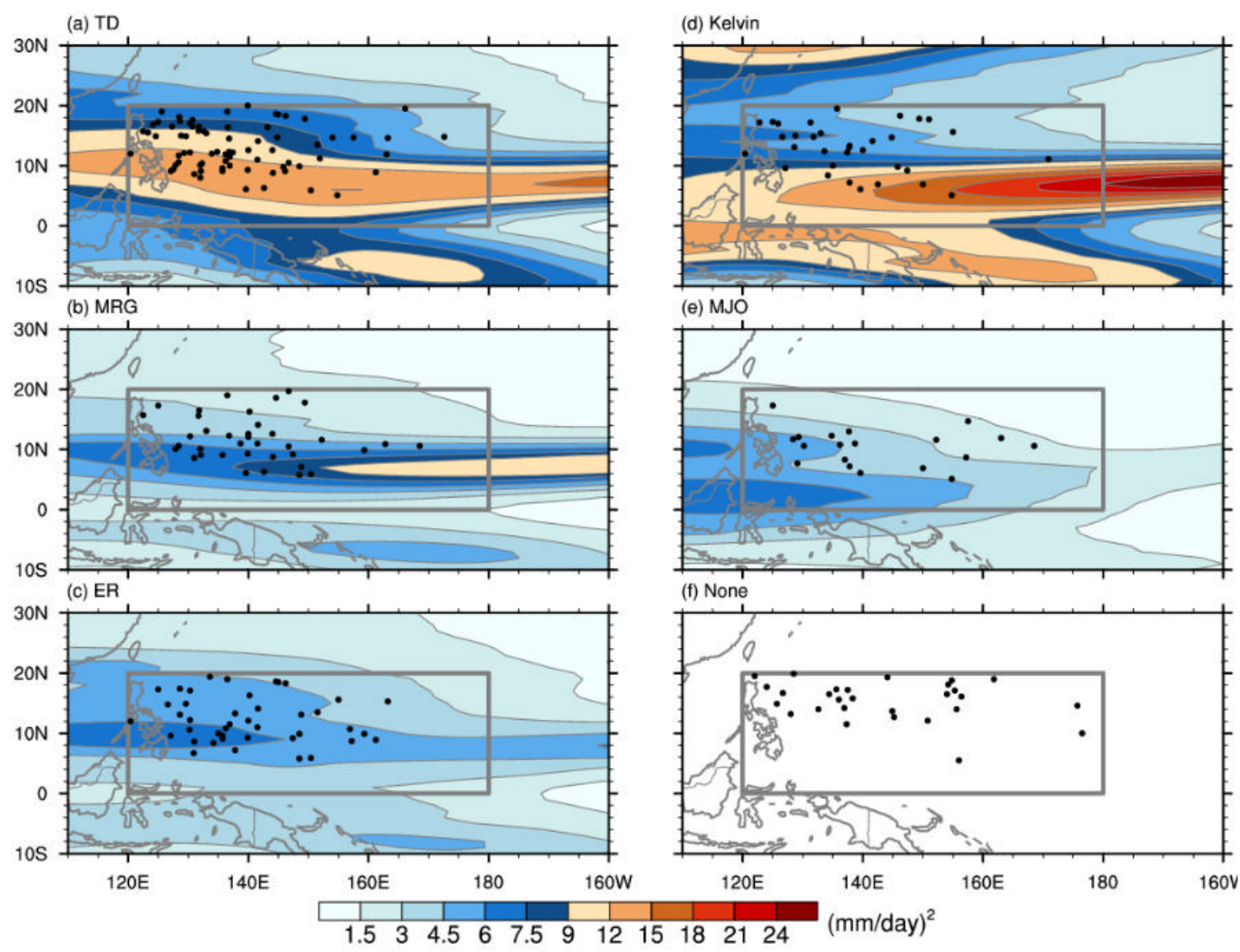

Figure 10. Genesis locations for tropical cyclones attributed to (a) TD-type disturbances, (b) MRG waves, (c) ER waves, (d) Kelvin waves, and (e) the MJO overlaid on the warm season variance for the given filter band. (f) Genesis locations for tropical cyclones that were not attributed to any equatorial wave. 


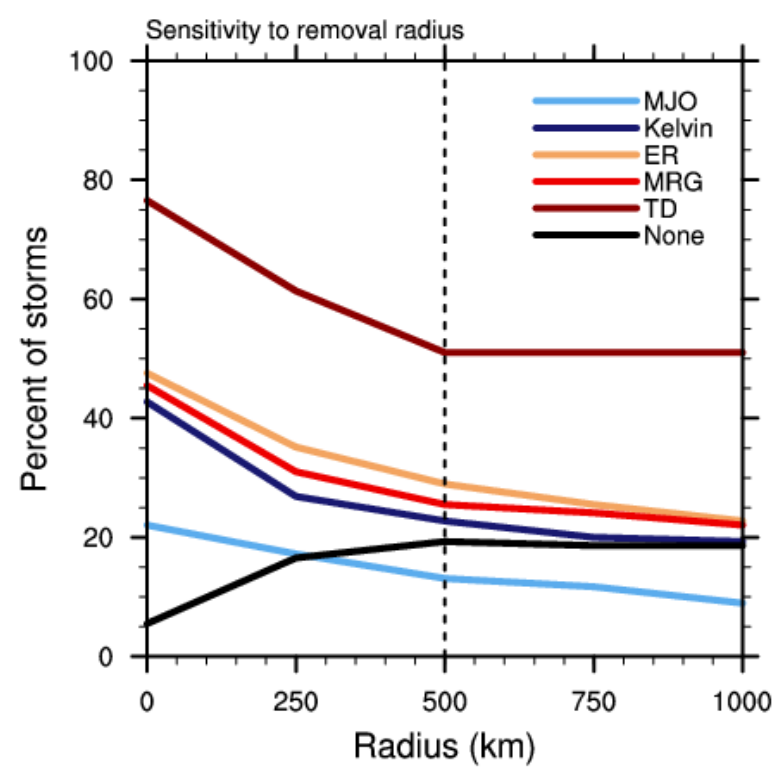

Figure A1. Percentages of storms attributed to the MJO (cyan), Kelvin waves (blue), ER waves (orange), MRG waves (red), TD-type disturbances (dark red), or no equatorial waves (black) as functions of the radius at half maximum for the tropical cyclone removal. All attributions use a threshold of $3 \mathrm{~mm} \mathrm{day}^{-1}$. 